07

\title{
Каскадные солнечные элементы на основе наногетероструктур $\mathrm{GaP} / \mathrm{Si} / \mathrm{Ge}$
}

\author{
() Л.С. Лунин, М.Л. Лунина, А.С. Пащенко, Д.Л. Алфимова, Д.А. Арустамян, А.Е. Казакова \\ Федеральный исследовательский центр Южный научный центр РАН, Ростов-на-Дону, Россия \\ E-mail: lunin_Is@mail.ru
}

Поступило в Редакцию 11 декабря 2018г.

В окончательной редакции 11 декабря 2018 г.

Принято к публикации 13 декабря 2018г.

\begin{abstract}
Методом импульсного лазерного напыления получены наногетероструктуры $\mathrm{GaP} / \mathrm{Si} / \mathrm{Ge}$. Проведено моделирование энергетической диаграммы каскадных солнечных элементов $\mathrm{GaP} / \mathrm{Si} / \mathrm{Ge}$. Выращенные на подложках $\mathrm{Si}$ нанослои $\mathrm{GaP}$ и $\mathrm{Ge}$ исследованы методом рамановской спектроскопии и рентгеновской дифракции. Изучены спектральные зависимости внешнего квантового выхода фотоответа наногетероструктур на основе $\mathrm{GaP} / \mathrm{Si} / \mathrm{Ge}$ для каскадных солнечных элементов.
\end{abstract}

DOI: 10.21883/PJTF.2019.06.47489.17635

Широкое использование солнечных элементов (СЭ) в энергетике сдерживается их высокой себестоимостью [1]. Существует два основных направления развития солнечной энергетики: 1) увеличение эффективности и спектральной чувствительности солнечных элементов; 2) уменьшение себестоимости СЭ.

В настоящее время хорошо известны успехи в создании эффективных СЭ на основе гетероструктур соединений $\mathrm{A}^{3} \mathrm{~B}^{5}$. Возможности дальнейшего повышения эффективности фотоэлектрического преобразования солнечной энергии связаны с разработкой каскадных элементов, созданных на основе гетероструктур $\mathrm{A}^{3} \mathrm{~B}^{5}$ с концентраторами излучения [2,3]. Одной из приоритетных задач современной фотовольтаики является снижение себестоимости каскадных СЭ с использованием кремния в качестве материала подложки и первого $p-n$-перехода многопереходного СЭ [4], а также поиск новых более дешевых технологий.

Целью настоящей работы является получение и исследование каскадных солнечных элементов на основе наногетероструктур $\mathrm{GaP} / \mathrm{Si} / \mathrm{Ge}$.

Для моделирования каскадных солнечных элементов использовалась программа AFORS-HET, позволяющая учитывать тип материалов, их электрические и оптические свойства, а также их толщину и степень легирования. Каскадные солнечные элементы состоят из верхнего перехода $\mathrm{GaP}$, подложки $\mathrm{Si}$, играющей роль среднего перехода, и нижнего перехода Ge, соединенных туннельными переходами (рис. 1, $a$ ). Верхний широкозонный слой фосфида галлия поглощает в основном коротковолновую часть спектра солнца, тогда как часть излучения с большей длиной волны поглощается более эффективно в кремниевом и германиевом переходах.

На рис. $1, b$ показана расчетная энергетическая диаграмма каскадных солнечных элементов $\mathrm{GaP} / \mathrm{Si} / \mathrm{Ge}$ при напряжении смещения $0 \mathrm{~V}$. Окно AlInP c большей шириной запрещенной зоны позволяет пропускать солнечное излучение без потерь, а также играет роль по- тенциального барьера для неосновных носителей заряда. Каскады соединены с помощью сильно легированного тонкого туннельного перехода с концентрацией доноров и акцепторов до $5 \cdot 10^{19} \mathrm{~cm}^{-3}$. Этот переход приводит к рекомбинации между электронами и дырками соседних каскадов и движению тока через структуру. Важным фактором является обеспечение баланса между скоростью рекомбинации и потоком поступающих носителей заряда, в противном случае возникает область объемного пространственного заряда, которая оказывает негативное влияние на электрическое поле каскада с более высокой скоростью генерации.

Наногетероструктуры $\mathrm{GaP} / \mathrm{Si} / \mathrm{Ge}$ были выращены на подложках $p$-Si (001) методом импульсного лазерного напыления. Данная технология выращивания наногетероструктур представлена нами в работах [5,6]. При напылении нанослоев $\mathrm{GaP}$ на подложку кремния $p$-типа проводимости в подложке формируется $p-n$-переход между подложкой $\mathrm{Si} p$-типа и приповерхностным слоем $\mathrm{Si} n$-типа проводимости, который возникает в результате диффузии атомов фосфора в подложку. Глубина залегания $p-n$-перехода составляет $120 \mathrm{~nm}$. Следовательно, в процессе импульсного лазерного напыления подложка кремния становится активной, т.е. образуется средний каскад солнечного элемента $n-\mathrm{Si} / p-\mathrm{Si}$ (рис. 1, a). Формирование нижнего германиевого каскада осуществлялось на предварительно выращенном слое $\mathrm{SiGe}$ по методике [5].

Полученные на подложках $\mathrm{Si}$ нанослои $\mathrm{GaP}$ и $\mathrm{Ge}$ были исследованы методом рамановской спектроскопии и рентгеновской дифракции. На рис. 2, а (вставка) приведены спектры комбинационного рассеяния света одного из образцов $\mathrm{GaP}$ на подложках кремния ориентации (001). В спектре присутствуют две полосы с частотами $364 \mathrm{~cm}^{-1}$ (ТO) и $404 \mathrm{~cm}^{-1}$ (LO), которые соответствуют собственным частотам колебаний чистого GaP. Наличие в спектре нанослоев $\mathrm{GaP}$ продольных колебаний (LO) 

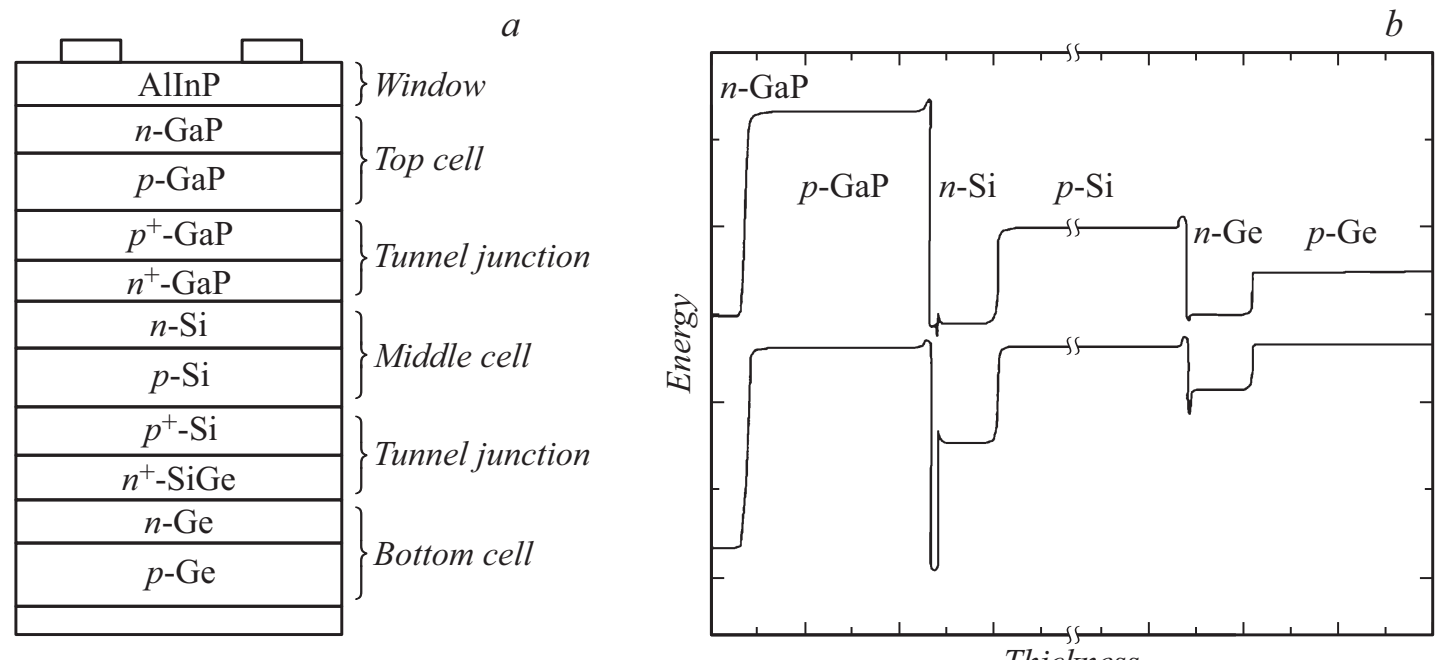

Рис. 1. Схема конструкции разрабатываемого солнечного элемента $(a)$ и его энергетическая зонная диаграмма $(b)$.
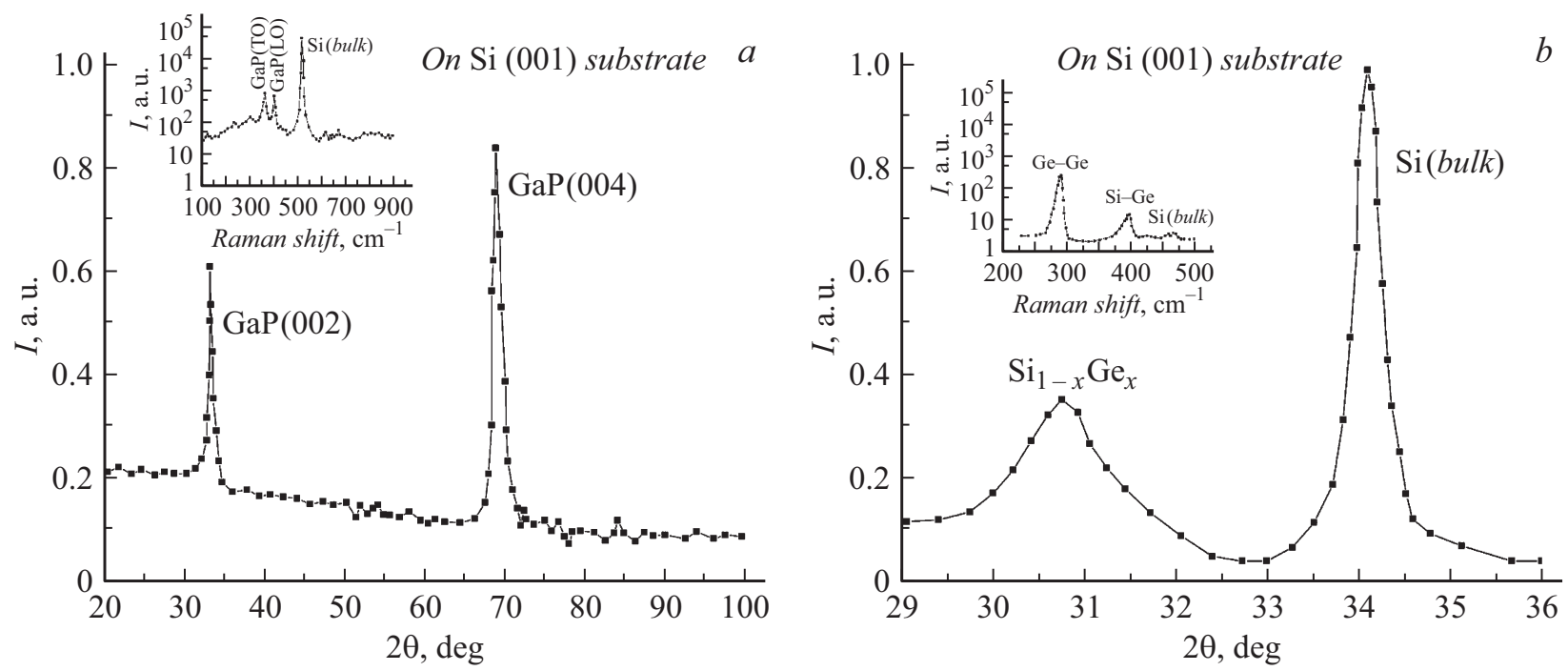

Рис. 2. Кривые дифракционного отражения $\mathrm{GaP}(a)$ и $\mathrm{SiGe}(b)$. На вставках — рамановские спектры $\mathrm{GaP}(a)$ и $\mathrm{SiGe}(b)$.

свидетельствует о довольно низком содержании примесей в них.

Присутствие четких дифракционных пиков (рис. 2, a) указывает на наличие кристаллической структуры нанослоев $\mathrm{GaP}$ с учетом значений дифракционных кривых на уровне половинной амплитуды.

Анализ морфологии выращенных нанослоев, проведенный методом атомно-силовой микроскопии, показал, что вследствие рассогласования параметров решетки материалов $\mathrm{Ge}$ и $\mathrm{Si}(\sim 4 \%)$ на поверхности полученных слоев наблюдался развитый рельеф. Шероховатость поверхности $(\sigma)$ зависит от эффективной толщины слоя и концентрации в пленках и изменяется в пределах 10-20 nm. При изменении эффективной толщины от 5 до $25 \mathrm{~nm}$ реализуется механизм упругой релаксации. С увеличением концентрации германия в эпитаксиальных слоях увеличивается рассогласование параметров решеток подложки $\mathrm{Si}$ и слоя $\mathrm{Si}_{1-x} \mathrm{Ge}_{x}$. Эпитаксиальный слой $\mathrm{Si}_{1-x} \mathrm{Ge}_{x}$ постепенно упруго релаксирует. Степень релаксации пленок $\mathrm{Si}_{1-x} \mathrm{Ge}_{x}$ оценивалась с помощью рамановской спектроскопии (рис. 2, $b$, вставка). Пик на частоте $\sim 280 \mathrm{~cm}^{-1}$ соответствует связи Ge-Ge. Он присутствовал на спектрах всех образцов, что указывает на наличие слоя германия. Пик на частоте $\sim 395 \mathrm{~cm}^{-1}$ свидетельствует о наличии связи $\mathrm{Si}-\mathrm{Ge}$. Связи $\mathrm{Si}-\mathrm{Si}$ отвечает пик с частотой $\sim 470 \mathrm{~cm}^{-1}$. Он проявляется для случаев, когда минимальные толщины пленок германия и $\mathrm{Si}_{1-x} \mathrm{Ge}_{x}$ меньше, чем глубина проникновения лазерного луча.

Анализируя морфологию поверхности и рамановский спектр наногетероструктур $\mathrm{Si}_{2} / \mathrm{Si}_{1-x} \mathrm{Ge}_{x} / \mathrm{Ge}$, можно определить глубину проникновения лазерного луча с длиной волны $\lambda=514.5 \mathrm{~nm}$. Если в рамановском спектре выращенных нанослоев $\mathrm{Si}_{1-x} \mathrm{Ge}_{x}$ и $\mathrm{Ge}$ не появляется пик, 


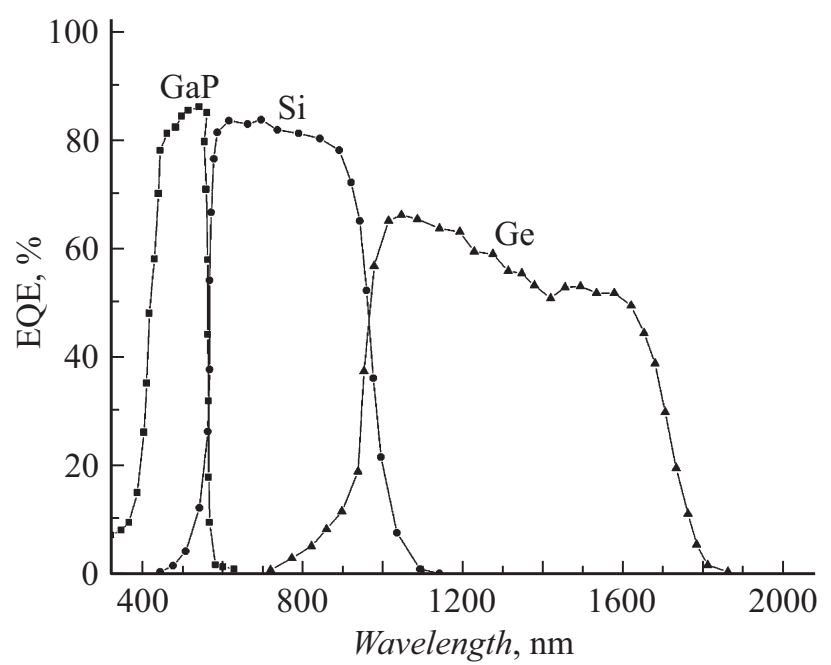

Рис. 3. Спектральная зависимость внешнего квантового выхода фотоответа трехкаскадного $\mathrm{C} Э \mathrm{GaP} / \mathrm{Si} / \mathrm{Ge}$.

соответствующий связи $\mathrm{Si}-\mathrm{Si}$, то минимальная толщина слоя является глубиной проникновения лазерного луча $(\lambda=514.5 \mathrm{~nm})$. В данном случае она достигает $40 \mathrm{~nm}$.

На рис. 2, $b$ показана типичная кривая дифракционного отражения (КДО) для наноструктур $\mathrm{Si}_{2} \mathrm{Si}_{1-x} \mathrm{Ge}_{x}$. Исследования показали, что интенсивность пиков Ge (и ширина КДО на половине высоты) возрастает с увеличением его концентрации и смещается в сторону увеличения угла 20. Присутствие четких дифракционных пиков указывает на наличие кристаллической структуры нанопленок $\mathrm{Si}_{1-x} \mathrm{Ge}_{x}$ и $\mathrm{Ge}$ с учетом значения ширины КДО на уровне половинной амплитуды $\left(\mathrm{FWHM}_{\mathrm{SiGe}}=44^{\prime \prime}\right.$ и $\left.\mathrm{FWHM}_{\mathrm{Ge}}=26^{\prime \prime}\right)$.

На основе гетероструктуры $\mathrm{GaP} / \mathrm{Si} / \mathrm{Ge}$ был создан трехкаскадный солнечный элемент, и измерена его спектральная характеристика (рис. 3). Использование узкозонного германия позволило расширить диапазон спектральной чувствительности вплоть до $1800 \mathrm{~nm}$, при этом внешний квантовый выход фотоответа нижнего каскада составил около 60\%. Максимальный внешний квантовый выход фотоответа верхнего каскада $\mathrm{GaP}$ в спектральном диапазоне 350-550 nm достигает 85\%.

Таким образом, методом лазерного импульсного напыления выращены трехкаскадные солнечные элементы на основе $\mathrm{GaP} / \mathrm{Si} / \mathrm{Ge}$, работающие в диапазоне длин волн от 300 до $1800 \mathrm{~nm}$. Методами рентгеновской дифракции и рамановской спектроскопии показано, что выращенные слои $\mathrm{GaP}, \mathrm{Si}_{1-x} \mathrm{Ge}_{x}$, $\mathrm{Ge}$ обладают кристаллической структурой.

Работа выполнена в рамках реализации ГЗ ЮНЦ РАН на 2019 г., номер госрегистрации проекта 01201354240, а также при финансовой поддержке РФФИ в рамках научного проекта № 17-08-01206 А.

\section{Список литературы}

[1] Jain N., Hudait M.K. // Energy Harvesting Syst. 2014. V. 1. N 3-4. P. 121-145. DOI: 10.1515/ehs-2014-0012

[2] Krier A., Yin M., Marshall A.R.J., Krier S.E. // J. Electron. Mater. 2016. V. 45. N 6. P. 2826-2830.

DOI: $10.1007 / \mathrm{s} 11664-016-4373-0$

[3] Алфёров Ж.И., Андреев В.М., Румянщев В.Д. // ФТП. 2004. T. 38. B. 8. C. $937-948$.

[4] Alferov Zh.I., Andreev V.M., Rumyantsev V.D. III-V heterostructures in photovoltaics // Concentrator photovoltaics / Eds A. Luque López, V.M. Andreev. Springer Ser. in Optical Sciences. 2007. V. 130. P. 25-50. DOI: 10.1007/978-3-540-68798-6_2

[5] Лунин Л.С., Лунина М.Л., Девицкий О.В., Сысоев И.А. // ФТП. 2017. Т. 53. В. 3. С. 403-408. DOI: $10.21883 /$ FTP.2017.03.44216.8299

[6] Лунин Л.С., Лунина М.Л., Казакова А.Е., Пащенко А.С., Алфимова Д.Л., Арустамян Д.А. // Письма в ЖТФ. 2018. Т. 44. B. 24. C. $75-80$. DOI: 10.21883/PJTF.2019.06.47489.17635 